\title{
Retraction Note: Landscape simulation of small towns along Huaihe River based on geographic information system and big data analysis
}

\author{
Chun $\mathrm{Ou}^{1,2} \cdot$ Xiamei Yao $^{1} \cdot$ Yuanyuan $\mathrm{Chen}^{1}$
}

Published online: 22 November 2021

C) Saudi Society for Geosciences 2021

Retraction Note: Arabian Journal of Geosciences (2021) 14: 608 https://doi.org/10.1007/s12517-021-06693-4

The Editor-in-Chief and the Publisher have retracted this article because the content of this article is nonsensical. The peer review process was not carried out in accordance with the Publisher's peer review policy. Author Xiamei Yao disagrees with this retraction. Authors Chun $\mathrm{Ou}$ and Yuanyuan Chen have not responded to correspondence regarding this retraction.

The original article can be found online at https://doi.org/10.1007/ s12517-021-06693-4.

Xiamei Yao

yaoxiamei1209@126.com

1 School of Architecture and Urban Planning, Anhui Jianzhu University, Hefei 230022, Anhui, China

2 School of Biology and Food Engineering, Fuyang Normal University, Fuyang 236037, Anhui, China 